\title{
LA IMAGEN VIRTUAL DE LA MUJER. DE LOS ESTEROTIPOS TRADICIONALES AL CIBERFEMINISMO
}

\author{
MARÍA CRUZ RUBIO LINIERS \\ CINDOC (CSIC) \\ Madrid (España)
}

La industria de la información electrónica, que comenzó en torno a los años sesenta del siglo XX, ha revolucionado de tal forma el mundo actual que podemos hablar de un antes y un después de la sociedad globalizada de la información. Y de todas estas tecnologías, Internet es el medio más poderoso de comunicación. La Red, que surgió como un medio de información científica, es hoy un universo plural, atemporal y globalizador donde conviven todas las ideologías, culturas y sociedades, un gran almacén de información y una forma de distribuir, influir y comerciar.

Se ha hablado mucho ya de la capacidad de manipulación de la imagen de la mujer en los medios tradicionales: prensa y televisión. Pero aún queda por analizar en profundidad de qué manera la Red crea, utiliza, define o modifica el imaginario social de género. Conocemos a través de estudios de mercado y encuestas de medios la presencia cada vez mayor de las mujeres como usuarias de estas tecnologías ${ }^{1}$, y sus preferencias y gustos a la hora de acceder a Internet, pero aún hay muy pocas mujeres concienciadas de la manipulación que sufren a través de las grandes multinacionales del negocio virtual, para convertirlas en consumidoras no sólo de productos sino también de ideologías.

Se dice, y es cierto, que Internet es el espacio perfecto para las mujeres y sus reivindicaciones: difícil de controlar y sin fronteras, permite un intercambio de opiniones ideas y conocimientos a través del correo electrónico, las listas de debate y los webs de información feminista. Pero no caigamos en la simpleza de pensar que la globalidad de las comunicaciones o la democratización aparente del medio representa la desaparición de las desigualdades de género. ¿Lo que intentan vendernos es aquello que realmente deseamos?, ¿o es lo que quieren que queramos?

1. http://www.gallup.es/encu_int.asp\#

Feminismo/s, 2, diciembre 2003, pp. 167-182 
El aspecto que aquí interesa desarrollar es qué imagen o imágenes de mujer presenta la información que navega por Internet. Vamos a analizar el tipo físico y social de mujer que nos muestra la Red, descubrir si su imagen es un reflejo de la realidad actual de las mujeres, o mantiene el estereotipo que advertimos en otros medios publicitarios, y si existen algunas peculiaridades derivadas de las características de la información virtual.

Algunos de estos temas fueron analizados en dos trabajos presentados anteriormente ${ }^{2}$, en donde a través del análisis de más de un centenar de webs y portales, algunos dirigidos al ocio masculino y otros específicamente a las mujeres, se mostraban los principales mundos virtuales donde la mujer es sujeto pasivo o protagonista activa. En este artículo se intenta ahondar en dichos imaginarios y ampliarlos desde la perspectiva del ciberfeminismo.

\section{LA IMAGEN «OSCURA» DE LA MUJER. PORNOGRAFÍA Y VIOLENCIA DE GÉNERO EN INTERNET}

La pornografía femenina, presente tradicionalmente en la prensa, cine o televisión, y que parecía haber sufrido un retroceso a partir de la denuncia de los grupos feministas y de las Declaraciones Internacionales por la igualdad de derechos, adquiere nuevamente en Internet un gran auge, con una dimensión más amplia y con mayores problemas de erradicación.

E1 26\% de los productos que se compran on-line son "para adultos». El negocio del sexo y la pornografía ha adquirido en Internet un gran auge, favorecido por el anonimato, la falta de legislación y la facilidad con que se pueden difundir y vender contenidos que incitan a la violencia física o psíquica. En 1999 los ingresos que provenían de la pornografía, los sex shows y los juegos interactivos para adultos fueron de miles de millones de dólares y para el año 2003 se estima que estas ventas se tripliquen y que generen la mitad de los ingresos provenientes de las ventas por correo electrónico ${ }^{3}$.

La fuerte competencia existente en Internet ha llevado a los pornógrafos a atraer la atención con imágenes cada vez más duras, de tortura, servidumbre y crueldad. Ya no es sólo la imagen estereotipada o la objetivación del cuerpo femenino, sino sobre todo su utilización como un objeto sexual que el hombre «salva, oprime, viola y domina ${ }^{4}$ ». A todas las formas de ejercer violencia sobre la mujer hoy puede añadirse la violencia virtual por ordenador, que puede llegar a convertirse en "violación virtual» ${ }^{5}$.

2. Rubio Liniers, María Cruz: «La imagen de la mujer en Internet», en Jornadas «Para (re)construir la imagen de las mujeres en la España Contemporánea. Facultad de Humanidades, Universidad Carlos III. 26-30 Mayo, 2001 y "La mujer en Internet: Viejos estereotipos y nuevas tecnologías», en IX Encuentro Andaluz de Formación Feminista. Baeza. Octubre, 2002.

3. Gubides Martínez, Olga: «Los videojuegos ¿̇alternativa a la soledad infantil?» en http://www.uaambit.org/linea.htm (Leído el 12 de marzo de 2003).

4. Gerstendöfeer, Mónica: «Violencia por ordenador», en .http://lolapress.org/artspanish (Leído el 10 de marzo de 2003).

5. Ibíd. 
Estas imágenes pueden ser manipuladas, modificadas y utilizadas como elemento de placer, por lo que la objetivización del cuerpo femenino va más lejos que en otros medios tradicionales y acostumbran al hombre a conseguir de la mujer cualquier capricho o deseo. Pero además, la mujer virtual, como objeto de placer, no es una verdadera mujer, por lo que la violencia y la manipulación están exentas de valoraciones morales. "El consumo de cyber-pornografía lleva a una insensibilización, a una falta de empatía o sea de ponerse en el lugar del otro" ${ }^{6}$.

Hoy proliferan los juegos eróticos que utilizan los llamados «parches», programas que permiten desnudar a sus heroínas. A imagen de las estrellas "porno» de videojuegos japoneses o ciberpunks, Internet va cada día más lejos, con programas interactivos como el Playmate que permiten conseguir experiencias cada vez más «reales» de cibersexo. En muchos casos, como Strip-O-Matic o Ultravixen, el jugador va desnudando a la mujer, creando según su deseo posturas provocativas e incluso actúa a través del ratón y la voz para conseguir llegar a los lugares más íntimos.

Aquí el usuario interviene y dirige la acción. No importa si utiliza látigos o penes artificiales disponibles en un «box» de herramientas. Las mujeres "virtuales» siempre disfrutan y exigen más acción. En Directors Cut puedes crear tu película y tus propios personajes femeninos. Y aún más lejos: un juego como Quake permite matar mujeres desnudas.

Los defensores de estos contenidos dicen que sólo accede a ellos el que quiere. Sin embargo, la facilidad de crear un «banner» o cartel con la dirección de un sitio pornográfico o de enviar correos no deseados es algo cotidiano y que conocemos por experiencia. Muchos servidores ofrecen alojamiento gratuito para estas páginas, cuya autoría es desconocida o aparece con nombre falso, por lo que no se puede perseguir ni castigar al delincuente.

Hay psicólogos que niegan la influencia de estos sitios en el aumento de la violencia contra las mujeres. Incluso algunos lo consideran como una forma de catarsis. Existe un gran debate sobre la ética y la permisividad de estos productos. En nuestra opinión los pornos interactivos pueden ser un método de aprendizaje social de imitación, ya que muchos jóvenes llegan a iniciarse en la sexualidad a través de las relaciones virtuales. Y ¿hasta qué punto realidad y virtualidad pueden llegar a confundirse? La violencia hacia las mujeres en Internet favorece la falta de cordialidad y de empatía hacia el otro sexo, y convierte en permisivas acciones que serían graves delitos en el mundo real.

Es cierto que muchos videojuegos están ofreciendo una nueva imagen de mujer menos sumisa, en ocasiones violenta y triunfadora.

«Pero ellas también están hipersexualizadas, con un marcado atractivo sexual, un cuerpo lleno de curvas. Además, curiosamente, algunas de estas guerreras de cómic pueden correr las mayores aventuras con unos tacones de aguja que en el mundo real apenas permiten desarrollar la velocidad de las mujeres chinas con sus pies defor-

6. Idem. 


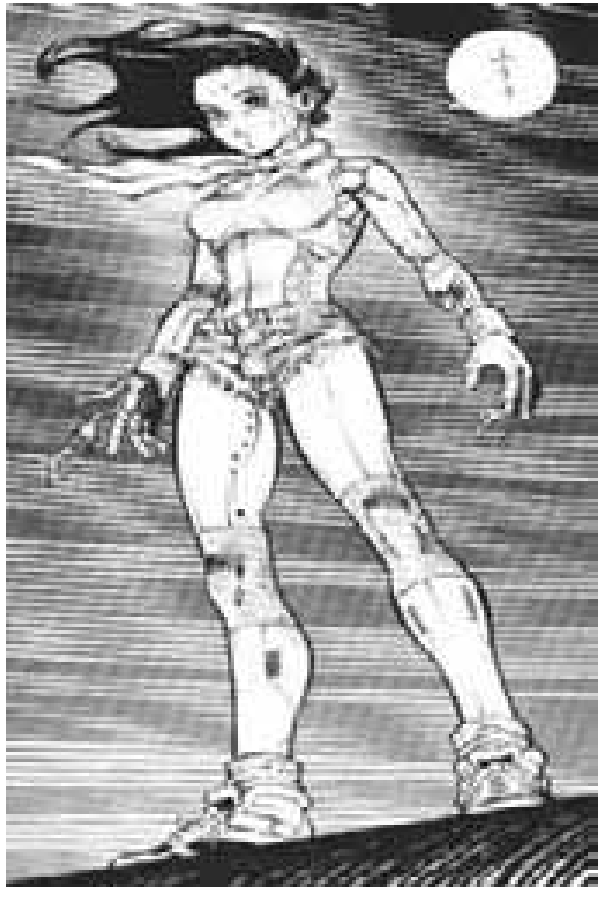

Fig. 1. mados desde niñas por los vendajes que impedían su crecimiento» ${ }^{7}$.

Tan generalizada está la utilización del cuerpo de la mujer en la publicidad a través de Internet que incluso su imagen se utiliza como reclamo para "servidores» gratuitos. Así, el distribuidor argentino Fullzero ofrece un servicio gratis de correo electrónico con la imagen de una mujer atractiva y debajo el texto "Fullzero hace realidad su deseo» ${ }^{8}$. ¿Cuál es hoy la imagen más utilizada como salvapantallas?: una mujer desnuda.

\section{INTERNET PARA LAS MUJERES. LOS PORTALES FEMENINOS: ESTEREOTIPOS TRADICIONALES}

En los últimos cuatro años, se ha pasado de carecer de recursos dirigidos expresamente a la mujer, a inundar la red con portales de temática exclusivamente femenina. Cuando parecía que la política de igualdad entre hombres y mujeres estaba consiguiendo en los países desarrollados importantes logros y cotas de aceptación, esta tendencia hacia la especialización puede parecer contradictoria.

La proliferación actual de los portales temáticos femeninos es considerada por la mayoría como una consecuencia de la mayor capacidad adquisitiva de la mujer. Estos sitios son fundamentalmente productos de marketing, de holdings editoriales o multinacionales de la comunicación que han advertido el crecimiento de las mujeres como usuarias de Internet y las consideran como potenciales consumidoras. En Estados Unidos, el 46\% de las compras on-line son hechas por mujeres. El prototipo de internauta es una madre de familia de raza blanca, entre los treinta y los cincuenta años, y con un alto poder adquisitivo. Muy pocos portales consultados se libran de la oferta de un «shopping» virtual para realizar las compras sin salir de casa.

Sólo en el ámbito de habla hispana hemos localizado más de sesenta portales dirigidos a mujeres e incluso un buscador Femina.com ${ }^{9}$ sobre recursos para,

7. Mguel, Ana de y Borx, Montserrat: «Los géneros de la red: los ciberfeminismos», en http: //www.dcc.uchile.cl/ rbaeza/libro/anademiguel.pdf

8. http://fullzero.ubbi.com

9. http://www.femina.com (Leído el 25 de marzo de 2003). 


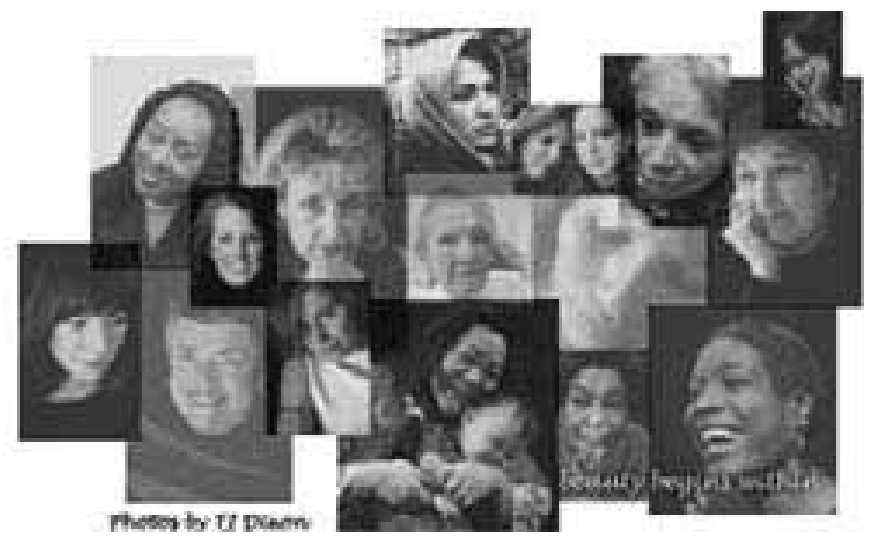

Fig. 2.

por y sobre mujeres. Incluso directorios y buscadores horizontales como Lycos, Navegalia, Yahoo, etc., se han decantado por apartados típicamente femeninos.

Están elaborados a imitación de sitios norteamericanos como ; Village.com ${ }^{10} \mathrm{y}$ wwwomen.com ${ }^{11}$, al parecer de gran éxito, por el número de visitas que reciben. Tan importante parece la rentabilidad de dichos portales que Microsoft ha lanzado un portal temático Women Central ${ }^{12}$ subtitulado Información para la mujer, casi exclusivamente dedicado, como los anteriores, a promocionar la venta de moda y artículos de belleza a través de la red.

El $90 \%$ de los portales consultados contienen como prioritarios los apartados de belleza, salud, cocina, maternidad y hogar, sexo, romance y pareja, astrología y cultura. Los apartados de mujer, belleza y dieta presentan un canon de belleza femenina muy similar a las que nos ofrecen las pasarelas de moda. Mujeres bellas, jóvenes y muy delgadas a las que se incita a gastar en cosméticos y cuidar su salud mediante la dieta, el deporte y la cirugía estética.

De mujer.com ${ }^{13}$ ofrece dietas para adelgazar más de diez kilos y promete como servicio estrella de la semana un chat con un cirujano plástico. Incluso en muchos de los apartados de salud, además de los problemas femeninos como menopausia o cáncer de mama, se insiste en la conveniencia de dietas y cuidados corporales y se informa sobre las operaciones de estética en los senos. "Pon tu ombligo a punto» dice Estar guapa.com ${ }^{14}$ y ofrece una guía de recursos en dietas de adelgazamiento.

Además de lo que representa esta imagen como estereotipo, son conocidos los estragos psicológicos que la dependencia de la figura física está provocando en las mujeres, sobre todo entre las jóvenes. Existe un buen número de sitios

10. http://www.ivillage.com/ (Leído el 25 de marzo de 2003).

11. http://www.wwwomen.com/ (Leído el 25 de marzo de 2003).

12. http://womencentral.msn.com/ (Leído el 25 de marzo de 2003).

13. http://www.demujer.com/cgi-bin/categoria.cgi?codigo=21 (Leído el 23 de marzo de 2003).

14. http://www.estarguapa.com/ (Leído el 25 de marzo de 2003). 
que denuncian el aumento de la anorexia y la bulimia. Es curioso y contradictorio que en los mismos portales junto a las dietas más variadas y junto a las modelos más esqueléticas se ofrezcan consejos médicos para evitar dichas enfermedades.

Pero también encontramos en Internet muchos sitios como Real Women Pro$j e c t^{15}$ que reinvindica una imagen más real, con este mensaje:

«imagina un mundo luminoso donde la verdadera belleza y el conocimiento de las mujeres sea conseguir la salud y la justicia para todas».

Aquí se revaloriza la "gordura» en las mujeres, y se denuncian los estragos que pueden producir la anorexia y la bulimia. Es el caso de Love Your Body Day ${ }^{16}$ o Adiós Barbie.com ${ }^{17}$, que enlazan con organizaciones feministas y fundaciones de ayuda que luchan contra los excesos de las dietas y del culto al cuerpo. Muchos de estos sitios, desde la ironía y la contracultura, apuestan no sólo por una imagen más real sino incluso por una ruptura de roles y estereotipos.

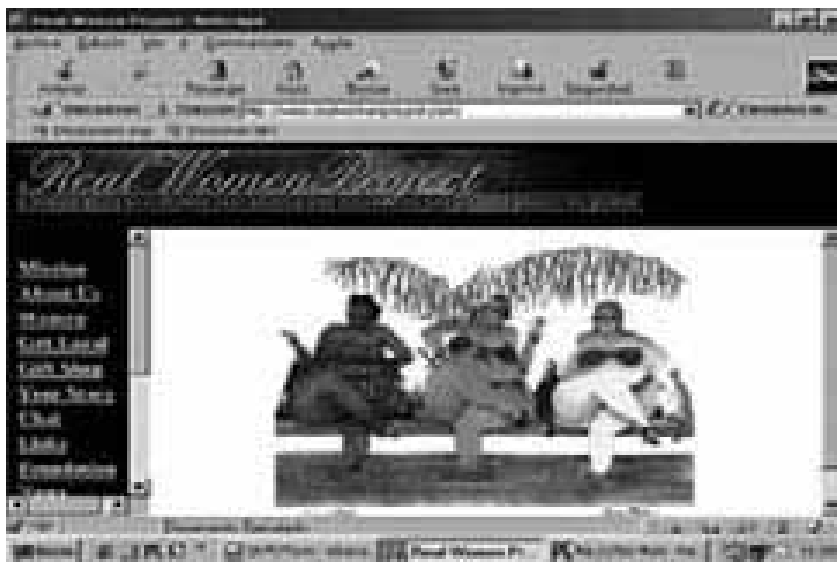

Fig. 3.

En la mayoría de las revistas virtuales femeninas existe un apartado sobre las relaciones sexuales y de pareja. Demujer. $\operatorname{com}^{18}$ pregunta en su editorial: "¿Los mujeriegos son más atractivos?» y presenta hechizos contra las penas de amor. "¿El sexo interesa más a las mujeres?» pregunta un artículo de Nosotras. Com ${ }^{19}$ al mismo tiempo que plantea "20 claves para dejarlo sin aliento». Este web tiene un consultorio sentimental. En Soloellas. $\mathrm{Com}^{20}$ se dice: "Revisa tu apariencia antes de la llegada de tu pareja» $\mathrm{y}$ "Haz ejercicio mientras haces la cama o pasas

15. http://www.realwomenproject.com/ (Leído el 25 de marzo de 2003).

16. http::// www.nowfoundation.org

17. http://www.adiosbarbie.com/ (Leído el 10 de abril de 2003).

18. http://www.demujer.com/cgi-bin/portal.cgi?codigo (Leído el 24 de marzo de 2003).

19. http://www.nosotras.com/ (Leído el 24 de marzo de 2003).

20. http://www.soloellas.com/combatelapresion01.html (Leído el 16 de marzo de 2003). 
la fregona. Levántate antes que el resto de tu familia y llévale el desayuno a la cama».

El cuidado de los niños y el hogar está también omnipresente en estos portales. Muchos reivindican en sus editoriales la lactancia natural. La macrobiótica y las medicinas alternativas están totalmente en boga y es interesante apuntar el auge de los portales temáticos y páginas sobre esoterismo, ocultismo o quiromancia. La mujer online.com ${ }^{21}$ ofrece una guía espiritual y está dedicada íntegramente al horóscopo, la numerología y el tarot.

Pocos de estos sitios introducen páginas culturales, y los que lo hacen, como informujer.com inciden principalmente en literatura escrita por mujeres. Los apartados de solonotras.com en cultura son: «Mitos y leyendas», "Poesías femeninas» y "Grandes mujeres». La mayoría de los sitios consultados además de tener muy poca calidad técnica carecen de enlaces interesantes. Soloellas ofrece como cultura en el número de febrero de 2003 una «Historia de la Coca Cola».

Respecto a la actualidad o las noticias se hace referencia únicamente a asuntos protagonizados por ellas o al inevitable mundo «rosa». Casi ningún portal analizado recoge temas de política nacional o internacional, aunque muchos de ellos van introduciendo noticias y enlaces sobre políticas de igualdad y violencia de género.

La incorporación masiva de las mujeres al ámbito laboral y profesional hace que la mayoría de los portales incluyan páginas de trabajo, formación profesional, empleo y creación de empresas. En estas páginas el tipo de mujer deja de ser la «top model» para convertirse en una mujer más «formal», aunque no menos estereotipada.

Paramujeres.com, ${ }^{22}$ en «los cinco secretos para tener éxito en una entrevista,» avisa sobre la necesidad de "evitar escotes y faldas cortas». Soloellas.com ${ }^{23}$ aconseja cómo decorar la oficina y conectadas.com ${ }^{24}$, en su artículo "Enseña a tu jefe a ser flexible», anima a conseguir trabajo en casa para compatibilizarlo con el cuidado del hogar. La imagen visual que ofrece este portal nos muestra al jefe-hombre rodeado por sus colaboradoras-mujeres. A pesar de definirse como una red creada por mujeres para «dar información y recursos que te ayuden en los negocios", presenta como tema principal de su primera página el artículo: "Dime cómo besa y te diré quién es».

Un ejemplo de esta imagen es la que declara mhmujer.com ${ }^{25}$, portal que aspira a ser el líder en lengua española:

«MHmujer.com es el portal en Internet de MH Mujer de Hoy, la revista femenina con más lectores de nuestro país y una tirada de 1.410 .300 ejemplares(e?). Mhmujer.com es un portal con el espíritu de la mujer del siglo XXI, lleno de ideas y de soluciones prácticas para la vida de la mujer de hoy. En MHmujer.com se encuentran

21. http://www.lamujeronline.com/ (Leído el 16 de marzo del 2003).

22. http://www.paramujeres.com/ (Leído el 21 de abril de 2003).

23. http://www.soloellas.com/dinero.html (Leído el 21 de abril de 2003).

24. http://conectadas.com/ (Leído el 16 de marzo de 2003).

25. http://www.mhmujer.com/ (Leído el 21 de abril de 2003). 
reflejados todos sus múltiples intereses desde la profesión a la familia, la economía, los hijos, las relaciones afectivas, la educación, la salud, la belleza, la moda o la decoración. Todo explicado de una manera sencilla y rigurosa, con la información de los mejores especialistas».

¿Y sus contenidos?: "De actualidad» (la ultima faena de Curro Romero), «Belleza» (novedades cosméticas para un cuerpo diez), cocina, horóscopos, hogar (guía útil para el cuidado de tu ropa) y moda.

En resumen, la mayoría de los portales femeninos analizados responden a una imagen tradicional de la mujer, cuando no absolutamente ñoña y cargada de cursilería. Una mujer físicamente perfecta, una Barbie de pasarela, preocupada principalmente de su dieta y gran consumidora de productos de belleza. Una mujer que continúa en su status tradicional de esposa y madre, pero que ahora debe compaginar todos estos aspectos con una formación cultural y profesional competitiva e igualitaria con el hombre. Una superwoman, que asume a la perfección la doble jornada y el doble papel que hoy se le exige, una mujer de transición, en crisis...

No extraña entonces que el servidor de Retecal incluya un apartado "MUJER ${ }^{26}$ con los siguientes enlaces: 1) Instituto de la Mujer, 2) Derechos de la mujer, 3) Revista Hmujer, 4) El embarazo, 5) La cocina de Carlos Arguiñano, 6) Contra los malos tratos, 7) Guía práctica para la familia y el hogar, 8)Dime que sujetador llevas y te diré quien eres.

Se ha dicho que el siglo XX ha sido el siglo de la mujer y que se está produciendo una feminización de la cultura. Parece que el siglo XXI ofrece la imagen de una "tercera mujer», profesional liberada, cargada de derechos y que sin embargo aún no ha conseguido liberarse de su cuerpo y de la carga negativa que responde a la oposición binaria masculino/femenino, racional/irracional, público/privado. Los medios de comunicación bombardean a las mujeres con la liberación a partir de la esclavitud de la imagen. Buscan una mujer perfecta que además proporciona pingües beneficios a las grandes multinacionales. Las nuevas diosas son las top-model, y la nueva religión el culto al cuerpo.

«La belleza femenina se contempla como algo importante no sólo para la vida privada de los hombres y de las mujeres, sino también para el propio orden social». "La mujer ya no acepta el machismo, no renuncia a sus derechos, pero al mismo tiempo sigue preguntándole al espejito quién es la más guapa» ${ }^{27}$.

\section{LAS CHICAS SON GUERRERAS. ¿NUEVOS ESTEREOTIPOS FEMENINOS?}

Frente a la imagen anterior están apareciendo en Internet una serie de grupos y movimientos más o menos contraculturales, sobre todo por parte de las más jóvenes.

26. http://users.servicios.retecal.es/uralde/mujer.htm (Leído el 21 de abril de 2003).

27. Lipovetsky, Gilles: La tercera mujer, Barcelona, Anagrama, 1999, p. 129. 
En una reciente investigación estadounidense sobre el comportamiento de las niñas ante las tecnologías se incluía un dato interesante: el $65 \%$ de las chicas dedica su tiempo libre a navegar por Internet. Existen cientos de sitios dedicados especialmente a las niñas entre los 13 y los 16 años.

Las menores se entusiasman por sitios de chat, juegos virtuales y revistas diversas que van desde algunas tradicionales como barbie.com o girlands hasta aquellas donde se permite navegar por civilizaciones virtuales, con imágenes de chicas tipo "guerreras del espacio", figuras de comics Manga o ciberpunks.

La pasión de estas jóvenes por Internet ha creado nuevas modas e imágenes: cybergrrls, webgrrls, riot girls, bad grrls o gurls. Todas ellas representan nuevas formas de representación femenina, aunque de muy distinta ideología y finalidad. Unas cercanas al cyberfeminismo, otras agresivas y muchas sin contextualización crítica alguna, juegan más bien a incorporar nuevas modas sexy o ambiguas, unas procedentes del pop, otras a imitación de los héroes cinematográficos y de la canción (Prince, Michael Jackson, etc.).

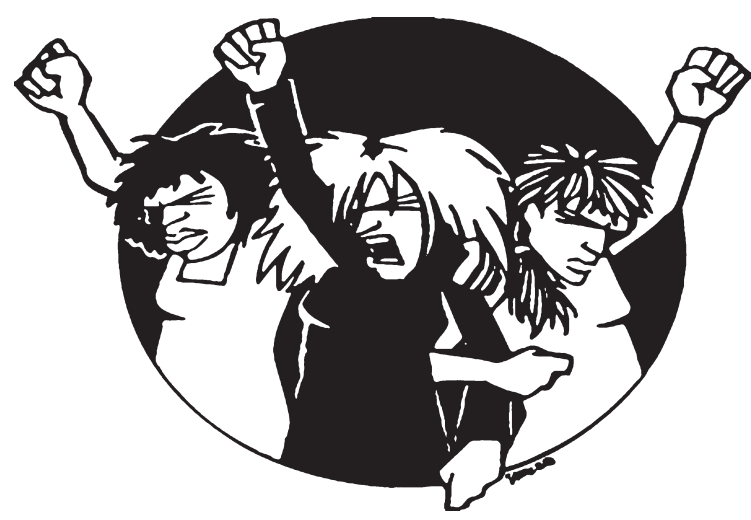

Fig. 4.

Las grrlls son el «último grito» de las chicas on-line. Presentan una imagen de poder y seguridad basado en el dominio de las nuevas tecnologías. Ser grrrl significa ser una chica muy "cool" con tenacidad para surfear la red, trabajar en línea con otras jóvenes y expandir las presencia de las chicas en las nuevas tecnologías de la información. Tienen foros de diálogo, debate e intercambio de experiencias, no sólo en torno a la informática sino a cualquier otro tema de interés para la juventud de hoy.

Las aventuras de CyberGrrl las define en términos de empoderamiento:

"CyberGrrl está en la Web para superarse a sí misma y para llegar a los otros. Pero ahora, en lugar de llegar a su familia y a su entorno inmediato, al lugar de trabajo y al barrio, puede llegar incluso más lejos y alcanzar a gente del resto del mundo con una acción tan simple como publicar su propia página o tan complicada como convertirse en una voz reconocida en la creciente sociedad de Internet ${ }^{28}$.

28. http://www.cybergrll.com 
Esa imagen desenfadada y crítica que intentan mostrar sus comics en muchos casos no es sino el intento de disfrazar problemas no superados con nuevas imágenes. Así las Gurp plantean a través de viñetas el principal problema que aqueja a las jóvenes de hoy, las relaciones personales y la imagen de su cuerpo. Este portal para chicas de 17 años presta una especial atención al mundo del físico, la sexualidad y las relaciones personales. Es realmente impresionante la importancia que le dan y los traumas que tienen por el mayor o menor tamaño de sus pechos y muchas manifiestan su empeño en operarse.

Kristine Blair y Pamela Takayoshi, en una interesante introducción ${ }^{30}$ a su libro Feminist Cyberscapes: Essays on gender in Electronic Spaces, opinan que estas imágenes continúan disociando la experiencia real del mito. Son metáforas de empoderamiento que las autoras consideran estrechamente definidas y alejadas de la realidad plural de las mujeres. Sus metáforas de fuerza, autoestima e inteligencia están ligadas a la imagen física de la superheroína delgada, blanca y políticamente correcta. Además muchos de estos sitios son círculos cerrados de poder, coaliciones y redes de "clubs» que excluyen a muchas mujeres, por su desconocimiento de las nuevas tecnologías, por su menor nivel económico o por pertenecer a otras culturas no occidentales.

Faith Wilding, referencia ineludible del cibermenismo, manifiesta también la parte negativa que estos movimientos tienen por su falta de ideología y debate político y se pregunta hasta qué punto representan otras imágenes, las de mujeres guerreras, igualmente esterotipadas ${ }^{31}$.

En una línea contracultural y feminista las Riot Girls defienden su oposición violenta al sistema patriarcal y su poder en el ciberespacio ${ }^{32}$ :

... «Yo, una chica disturbio, una chica mala, quiero un imaginario propio, un ser proyectado independiente. Quiero diseñar el mundo a mi gloriosa imagen. Llegó la hora del matrimonio impuro entre la Ariadne de Nietzsche y las fuerzas dionisíacas; llegó el momento de que la pulsión de muerte femenina se manifieste en el establecimiento de redes factibles para la transformación del deseo femenino en formas de conducta negociables con la sociedad. Llegó el momento de que el inconsciente haga un nuevo pacto».

«Sí, las chicas se están cabreando: reivindicamos nuestros cibersueños, nuestras alucinaciones compartidas. Podéis quedaros con vuestra sangre y vuestro gore, lo que nos importa a nosotras es cómo hacernos con el ciberespacio para salir del cadáver viejo, decadente, seducido, abducido y abandonado por el patriarcado logocéntrico: los escuadrones fálicos de la muerte, la falocracia, con su cuerpo de militantes hinchados de silicona, geriátrico, materialista y su 'otro' femenino anexionado e inventariado. Las chicas disturbio saben que se merecen algo mejor».

29. http://www.gurl.com/connect/bbs/bb.epl/gurlV3/default?Sess

30. BaIR, Kristine y TaKayoshI, Pamela: «Navigating the image of Woman Online», en http:// english.ttu.edu/kairos/2.2./coverweb/invited/kb5.html

31. Notas sobre la condición política del Cyberfeminismo - Faith Wilding \& Critical Art Ensemble, en http://www.estudiosonline.net/texts/index.htm

32. http://www.e-leusis.net/monografías_ver 


\section{OTROS CUERPOS, OTRAS METÁFORAS. DE-CONSTRUYENDO LA IMAGEN DE LA MUJER DESDE EL CIBERFEMINISMO}

El ciberfeminismo es un movimiento con muchas variantes y estrategias pero que tiene como elemento común la utilización de las nuevas tecnologías para la liberación de la mujer. Internet es para las ciberfeministas el medio idóneo de conseguir el poder. Organizadas en redes y clubs cibernéticos, muchas de ellas se encuadran en una nueva forma de feminismo que, con múltiples ideologías y tendencias, tienen algo en común. Es, en palabras de Sadie Plan «la cooperación, para su liberación y empoderamiento, entre mujer, máquina y nuevas tecnologías» ${ }^{33}$.

En su obra Ceros y Unos, Plant mantiene que la informática es fundamentalmente femenina y plantea la relación histórica entre mujer y tecnología, desde la telefonía, el telar eléctrico y la máquina de escribir hasta los ordenadores ${ }^{34}$. Además de propugnar la subversión del sistema patriarcal y jerárquico, intentando aproximarlo a la estructura descentralizada, compleja y múltiple de la Red, este ciberfeminismo social reivindica las características femeninas como idóneas para controlar Internet, no sólo por sus posibilidades de comunicación y expresión sino también porque los atributos físicos no importan en el ciberespacio.

La Red es una demostración de cómo lo jerárquico está siendo superado por un nuevo sistema de organización; una estructura más compleja, la estructura de rizoma, que imita el mecanismo sobre el que las mujeres construimos el conocimiento y la información. Las mujeres saltamos de un plano a otro sin dificultad, de lo cotidiano a lo institucional, de lo oficial a lo privado. Es la capacidad de realizar varias tareas simultáneas sin distraernos. Puede que se esté rearfirmando un modelo de conocimiento basado en un nuevo paradigma, que a imitación del hipertexto sea capaz de reunir el pluralismo de las situaciones.

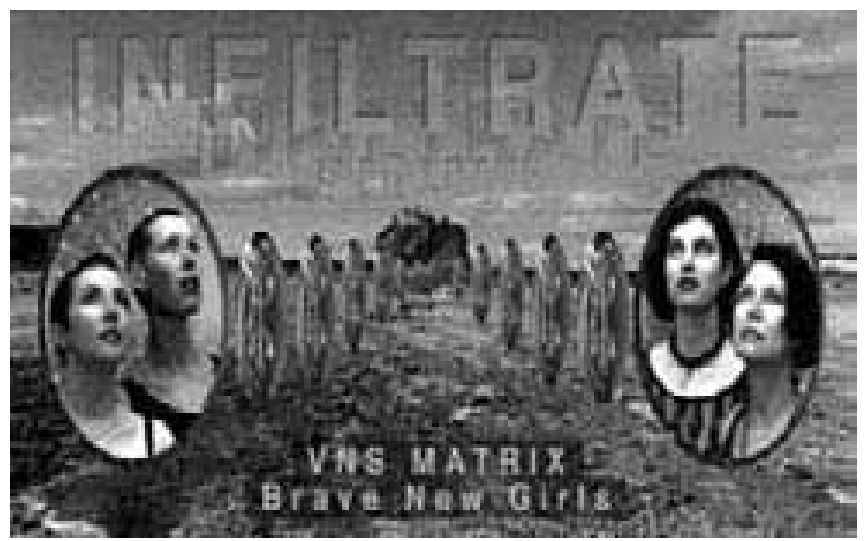

Fig. 5.

33. Plant, Sadie: Ceros y Unos, Barcelona, Destino, 1998, p. 17.

34. Ibíd. 
"Vigilar ininterrumpidamente lo que se hace, sin dejarse absorber completamente» como escribía Simone Weil en sus cuadernos.

La organización rizomática de la matriz y las teorías de Sadie Plant equiparando la matriz de cálculo de los ordenadores con la matriz femenina, llevó a las pioneras ciberfeministas VNS MatriX a propugnar en su «Manifiesto de la Zorra/Mutante» (1990) una provocativa alianza entre el cuerpo de la mujer y la máquina: «el clítoris es una línea directa a la matriz» ${ }^{35}$.

La importancia del cuerpo y su imagen en el discurso feminista lleva a un interesante debate teórico relacionado con los géneros y su imagen en la red. Rosi Braidotti ${ }^{36}$ defiende la importancia de la tecnología como algo material y simbólico, como un agente semiótico y social más, prolongación de lo humano que a través de la utopía y un nuevo simbolismo corporal permita:

«una estrategia para liberar nuestra imaginación colectiva del falo y sus valores accesorios como son el dinero, la exclusión y la dominación, el nacionalismo, la feminidad icónica y la violencia sistematizada».

Braidotti plantea el origen de las diferencias de género en la distinta conceptualización de la entidad masculina y femenina. El hombre es el «ser» completo, el sujeto humano, cuya trascendencia está más allá del cuerpo. La mujer es el "otro", subjetivado o negado, encarnado en un cuerpo femenino y limitado al deseo. Por ello es necesario enterrar el eterno femenino y crear nuevas utopías y metáforas desde la ironía, la parodia y la deconstrucción de la imagen física tradicional.

La importancia del cuerpo y su imagen en el discurso ciberfeminista lleva a un grupo de mujeres encuadradas en el postmodernismo y el postestructuralismo a plantear la subversión de los estereotipos, presentando una nueva imagen "posthumana» del cuerpo, más allá del icono "Mujer blanca, cuerpo Danone» y del binomio masculino/femenino. Se busca la transformación de la imagen

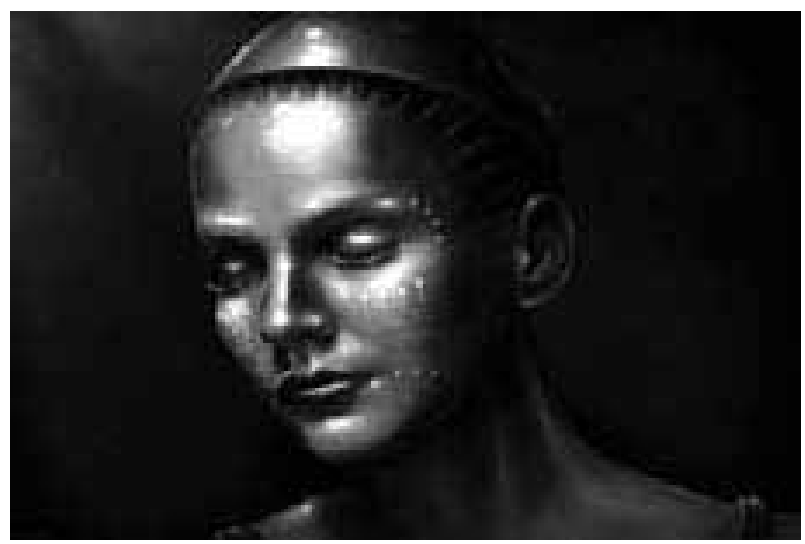

Fig. 6.

35. "Manifiesto de la Zorra Mutante», en http://www.sysx.org/vns/manifesto.html 36. Braidotti, Rosi: «Un ciberfeminismo diferente», Debats, 76 (2002), pp. 100-117. 
física de las mujeres, la inversión de los estereotipos y la reconstrucción del cuerpo en el ciberespacio postsexual.

En la línea más radical de este pensamiento está Dona Haraway, filósofa y feminista americana, que propone una nueva relación con la máquina, entre lo natural y lo artificial, y por extensión, una nueva teoría -o ética- de la identidad. En su ensayo ya clásico, "Manifiesto Cyborg» (1991), identifica un nuevo tipo de feminismo inspirado en la imagen del cyborg, entendido como un organismo cibernético, un híbrido de la máquina y el organismo, una criatura tanto de la ficción como de la realidad social ${ }^{37}$.

La idea que Haraway propone es que el concepto de cyborg vuelve borrosos los límites entre el ser humano y la máquina, y ello eventualmente volverá obsoletas las categorías de varón y hembra, abriendo el camino a un mundo de libertad, más allá de los géneros. "Somos todos quimeras, híbridos teorizados y fabricados de máquina y organismo. En otras palabras, todos somos cyborgs». "Antes que diosa prefiero ser cyborg», dijo Haraway, y en este sentido estaba haciendo también una crítica irónica al feminismo de la diferencia de princi-

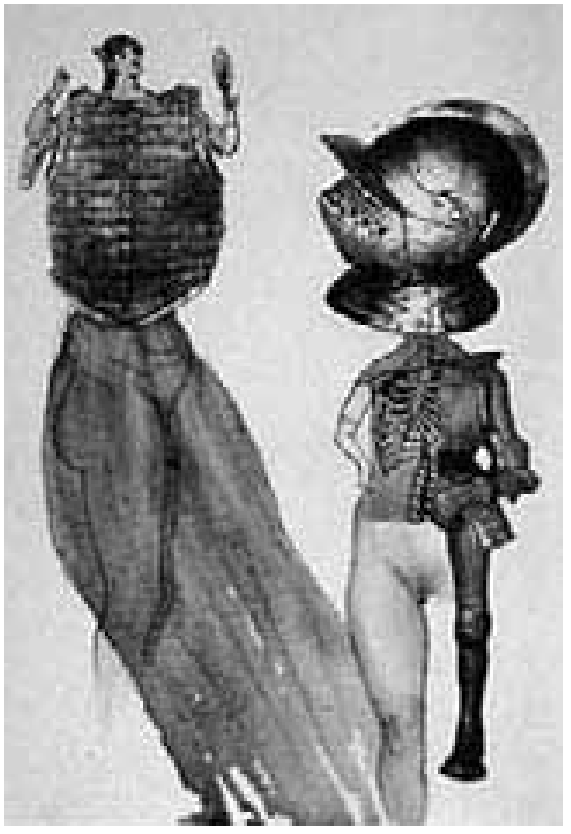

Fig. 7. pios de los noventa. El cyborg no está mediatizado por la bisexualidad, pero tampoco por la naturaleza ${ }^{38}$.

Sin embargo, esta salida del laberinto de los dualismos con el "posthumanismo", esta atractiva utopía postgenérica, también puede feminizarse nuevamente y recrear, como dice Ana Martínez Collado, imaginarios que no siempre benefician a las mujeres ${ }^{39}$. En el caso de la ciencia ficción, las fantasías sobre el cuerpo femenino están relacionadas con el cuerpo reproductivo. Fantasías monstruosas que pueden volver a recrear géneros virtuales, programados para reproducir la realidad externa a la red. Esto se demuestra en la existencia de juegos por ordenador que incorporan la utilización de "parches» para añadir pechos, feminizando y sexualizando de nuevo la imagen del cyborg.

37. Texto electrónico del «Manifiesto Cyborg» en http://www.iade.org.ar/iade/Dossiers/imperio/ 5.6.html

38. Ibíd.

39. Martínez Collado, Ana: «Subjetividad y tecnología en el arte contemporáneo hecho por mujeres», Debats, 76 (2002), pp.140-149. 
Resulta muy acertada la opinión de Sandy Stone, que defiende la idea de que las nuevas tecnologías no son agentes trasparentes que eliminen el problema de la diferencia sexual, sino medios que promueven la producción y organización de cuerpos sexuados en el espacio, y que las metáforas virtuales no son sino una prótesis, prolongación de nuestro espacio físico habitual. Para ella la red es un lugar de migración y transformación corporal ${ }^{40}$.

Faih Wilding ${ }^{41}$ y el Critical Art Ensemble encabezan un movimiento de artistas que intentan aplicar las posibilidades de la creación artística virtual y construir un ciberespacio simbólico para la transformación del referente corporal y sexual femenino.

Ars Electrónica 2000 y el grupo CAE trabajan en "Biotech Proyects» ${ }^{42}$ : foros de discusión y perfomances sobre el tema de sexo, género y tecnologías reproductivas y en el proyecto "Culto de la nueva Eva» que desmitifica el personaje judeo-cristiano y busca un nuevo prototipo de mujer real para el tercer milenio, donde sexualidad y procreación estén claramente distanciadas.

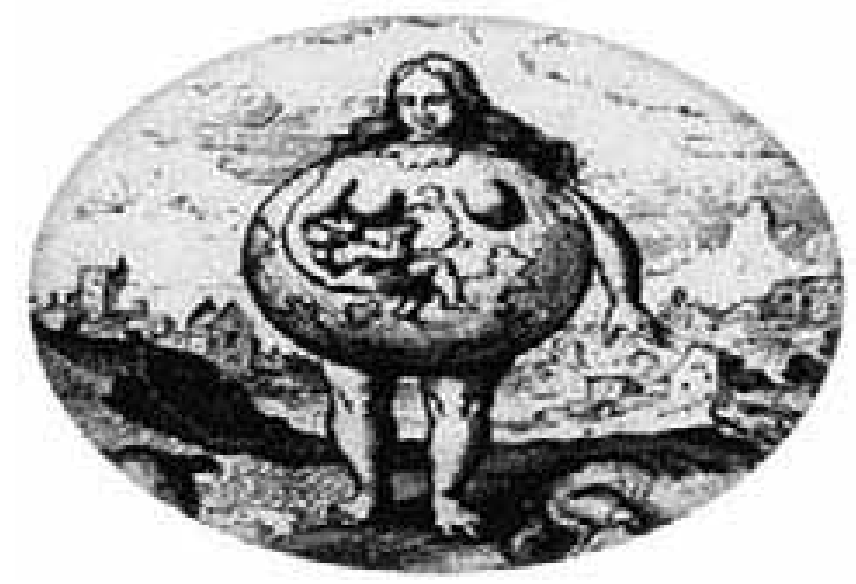

Fig. 8.

Muchas artistas están investigando el cuerpo de la mujer desde el net-art o el postexpresionismo. Además de la mencionada Faith Wilding, podemos nombrar a Shelley Jackson ${ }^{43}$, Francesca da Rímini ${ }^{44}$, Tina Laporta y su tan conocido «Future Body» ${ }^{45}$, Eva Wohlgremuth ${ }^{46}$ o Vanessa Beecroft ${ }^{47}$.

40. Stone, Sandy: «Will the Real Body Please Stand Up?», en Michael Benedikt (ed.): Cyberspace. First Steps, Cambridge, Mass, MIT Press, 1992, pp. 81-118.

41. http://www-art.cfa.cmu.edu/www-wilding/ (Leído el 26 de marzo de 2003).

42. http://www.critical-art.net/biotech/sra/SRAweb/index.html (Leído el 25 de marzo de 2003).

43. http://www.altx.com/thebody/ (Leído el 25 de marzo de 2003).

44. http://z.parsons.edu/\%7Eludin/final_pages/ (Leído el 7 de abril de 2003).

45. http://users.rcn.com/laporta.interport/futurebody.html (Leído el 7 de abril de 2003).

46. http://thing.at/bodyscan/personal_1_0/index.htm (Leído el 8 de abril de 2003).

47. http://www.vanessabeecroft.com/ (Leído el 7 de abril de 2003). 


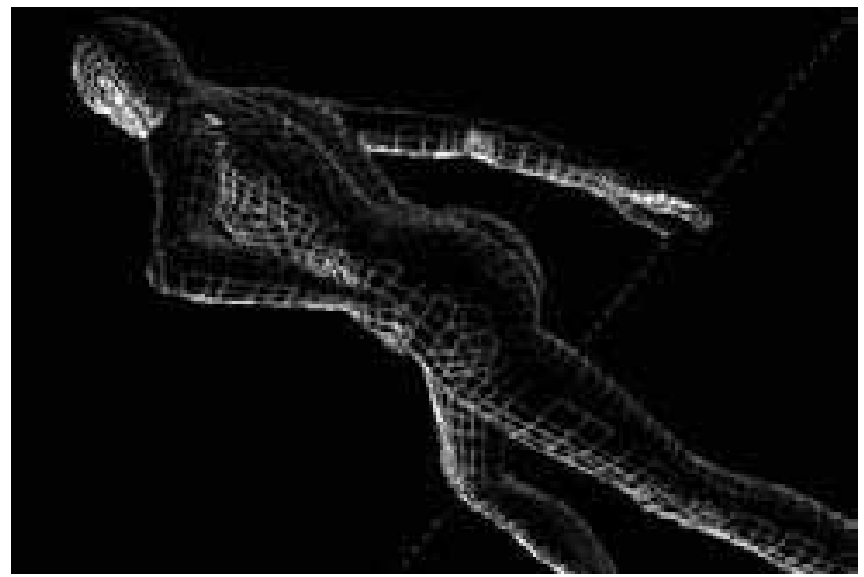

Fig. 9.

Pero a pesar del indudable interés de estas corrientes artísticas, es más importante, como mantiene la propia Wilding ${ }^{48}$, luchar contra la clasificación genérica más desde lo conceptual que desde lo físico, ya que ¡hasta qué punto un nuevo imaginario femenino puede desembocar en nuevos roles de género?

Aún el cuerpo de la mujer continúa siendo sólo una imagen impuesta, un reflejo del deseo masculino. Su existencia, su sustancia, su entidad depende aún de la mirada del otro y la lucha contra el patriarcado continúa y se reproduce en la red.

Como decíamos al principio, Internet no es sino un espejo virtual donde se reflejan todas las imágenes femeninas. Imágenes de placer para el hombre, de mujeres objeto, diosas o top-girls. Imágenes de chicas guerreras, perfomances o cuerpos post-genéricos de cyborg. Y detrás subyacen imaginarios tradicionales o de ruptura, protesta y cambio.

Es importante deconstruir esta imagen corporal impuesta y colectiva, y soñar nuevas utopías, pero sin olvidar que lo fundamental es el cambio social, político y cultural que lleve a la igualdad y al respeto de las identidades personales. Es fundamental la crítica a los imaginarios colectivos y a los roles de género; es necesario cambiar la imagen y también la palabra. Pero parafraseando un dicho popular "el movimiento se demuestra navegando», y esto significa conquistar la Red y transformar el poder masculino clasificatorio y jerarquizado genéricamente. Fomentar la comunicación entre mujeres a través de Internet, crear redes de solidaridad y denuncia, redes de información con contenidos feministas y luchar por la formación e incorporación de las mujeres a las nuevas tecnologías son algunos de los más importantes y prioritarios desafíos aún por conquistar.

48. WLDing, Faith: «Duration Perfomance: La economía del mantenimiento del trabajo femenino», en Estudios online sobre arte y mujer ( http://www.estudiosonline.net/texts/wilding.html). 


\section{BIBLIOGRAFIA}

Stone, Sandy: «Will the Real Body Please Stand Up?», en Michael Benedikt (ed.): Cyberspace. First Steps, Cambridge, Mass., MIT Press, 1992, pp. 81-118.

- «El imperio contraataca. Un manifiesto posttransexual», en Estudios on line sobre arte (http://www.estudiosonline.net/texts/stone_manifiesto.htm).

- The War of Desire and Tehcnology at the Close of the Mechanical Age, Cambridge, Mass., MIT Press, 1995.

Braidotti, Rossi: «Un ciberfeminismo diferente», Debats, 76 (2002), pp. 100-117.

Galloway, Alex: «Un informe sobre cyberfeminismo. Sadie Plant y VNS Matrix: análisis comparativo", en: Estudios on line sobre arte y mujer (http://www.estudiosonline.net/ texts/).

HaraWay, Dona: "Manifiesto para Cyborgs», en Ciencia, cyborgs y mujeres. La reinvención de la naturaleza, Cátedra, Madrid, 1995, pp. 149-181.

MArco, Gisela di: "Cybergrrls y la re-presentación del sujeto», en http:// betatesr.ubp.edu.ar/

Martínez Collado, Ana: «Subjetividad y tecnología en el arte contemporáneo hecho por mujeres», Debats, 76 (2002), pp. 139-149.

- «Cyberfeminismo: Dos escenarios» en Estudios online sobre arte y mujer (http:// www.estudiosonline.net).

Miguel, Ana de y Borx, Montserrat: "Los géneros de la red: los ciberfeminismos», en www.dcc.uchile.cl/ rbaeza/libro/anademiguel.pdf

Plant, Sadie: «Reflexión sobre mujer y realidad virtual», en, Creatividad Feminista (http: //www.creatividadfeminista.org/articulos/ciber_realidadvirtual.htm).

SEnFT, Teresa: «Interpretando el cuerpo digital», en Estudios on-line sobre arte y mujer (www.estudiosonline.net).

SMELIK, Anneke: "The caruosel of genders», en www.let.uu.nl/womens_studies/anneke/ carous.htm

Vidal Claramonte, África: «Diosas, top moldels y mutantes», Debats, 76 (2002), pp. 128-137.

WiLDING, Faith: "Notas sobre la condición política del cyberfemenismo», en Creatividad Feminista (http://www.creatividadfeminista.org/articulos/ciber_artensamble.htm). 